\title{
Process Design of Cooperative Education Management System by Cloud-based Blockchain E-portfolio
}

\author{
https://doi.org/10.3991/ijoe.v15i08.10374
}

Sukosol Wanotayapitak $\left.{ }^{\varpi}\right)$, Kobkiat Saraubon, Prachyanun Nilsook King Mongkut's University of Technology North Bangkok, Bangkok, Thailand sukosol@yahoo.com

\begin{abstract}
The digital competence is necessary for 21 st century living, but from several countries survey, a large number of people still have insufficient digital competence. Moreover, from literature study found three problems of today cooperative education information system, (1) lack of information sharing among university community, (2) lack of connect information to public, and (3) lack of enhancing 21 st century learning skill. This paper proposes a process design of cooperative education management system by using the integration of cooperative education, E-Portfolio, digital competence framework 2.0, cloud computing technology, and blockchain technology. These processes make result of digital competence assessment credible and share to open digital labor market finally.
\end{abstract}

Keywords - Cooperative education, E-Portfolio, Blockchain technology, Cloud computing technology, Digital competence, Open digital labor market

\section{$1 \quad$ Introduction}

The lack of necessary skills for working is the main cause of unemployment problem. In the 21st century, social and economic conditions are transformed into digital that affect to necessity for develop additional skill more than previous generations that called 21st century learning skill [1]. However, at present, most of the world's population still has not enough digital skills to live in a digital society. As seen in the 2015 report from Europe [2], although it is a region with a high standard of education, nearly $44.5 \%$ of the population or nearly half between the ages of 16 and 74 , have inadequate digital skills for social and economic well-being.

From the beginning of the 20th century, the concept of managing education curricula was developed in response to a labor market called cooperative education. It is found that cooperative education can improve the graduation process to enter the labor market effectively and meet the needs of the workforce of entrepreneurs. Therefore, when entering the digital era in 21st century, there is a new issue that apart from focusing on professional competencies, "how can cooperative education promote digital competence?" This research aims to design a process to develop a cooperative education system that can enhance the assessment of digital competence. Moreover, it also contributes to a shared economy and led to the open digital labor market as the 
future labor market model by integrating of cloud computing technology, blockchain, and E-Portfolio into cooperative education.

\section{$2 \quad$ Literature Review}

\subsection{Cooperative education}

Cooperative education is a program that deals with undergraduate students who are required to work full-time and relate to the core curriculum as an educational program. The cooperative education program provides an opportunity for students to integrate their work into their academic experience. Opportunities that come from working make the students experience situations that led to a deeper level of learning [3]. Therefore, cooperative education is a structured learning strategy that integrates classroom learning into learning through hands-on experience in relation to students' academic and provides an improved experience in integrating theory into practice [4].

Cooperative education E-Portfolio: The role of E-Portfolio is to provide general learning evidence and provide a set of personal digital information materials to demonstrate the learning process, experience and achievement of learners for career goals and personal development [5]. There are several researches supporting the application of E-Portfolio to cooperative education program, e.g. the integration of EPortfolio into cooperative education programs from the interdisciplinary perspective of the college of language and social sciences, university of technology, Auckland [6], the presentation of course activities to enable students to show their learning results in the form of feedback reports on E-Portfolio, which is used as a medium for promoting student confidence in accordance with the preparation for doing work report in the context of cooperative education program [7].

E-Portfolio Assessment in cooperative education: E-Portfolio is used as a tool to assess cooperative education because it can reflect the authentic competence from workplace. At the same time, students can use their E-Portfolio capabilities to present their work with digital media freely that can be seen as concrete. From research study, there are found several studies that apply E-Portfolio to help assess cooperative education, e.g. the center for career education at Windsor University of Canada use EPortfolio as part of cooperative education programs to reflect student activity and resources for assessing achievement, a study of professional competence assessment in work-integrated learning by collaborative assessment of E-Portfolio including reports of workplace on what students use to confirm their abilities and the evidence of competence that the advisor gathered [8].

\subsection{Digital competence framework 2.0}

The lack of digital skills affects the way people live and work and this problem has occurred to several countries around the world. In European survey [9] found that people with inadequate digital skills up to $40 \%$ and no digital skills at all up to $22 \%$ which is found in the elderly or young people at low education, low income families, 
and migrants. Moreover, $32 \%$ of the workforce in Europe had inadequate digital skills, and $13 \%$ is judged as having no digital skills when evaluated.

The digital competence framework for the people of Europe has introduced digital competence improvement tools for the public. This framework document presents digital 2.0 competence focused on reference models, concepts, terminology, and new descriptions. It also demonstrates example of how digital competence is being used in European and regional nations. Digital competence was developed by the Joint Research Center (JRC) of the European Commission as a scientific project based on broad consultation with stakeholders and policy makers from industry, education, employment training, and social partnerships [10].

\subsection{Cloud computing technology}

Cloud computing is the Internet-based process in which hardware and software resources are provided to users as needed that come from the ease of access to remote processing sites provided by the Internet. Cloud computing makes it possible to use the Internet-delivered software on the browser without any installation and stored host on the Internet and can be installed remote file storage, and so on [11].

The trend of cloud computing is growing continuously. According to the survey [12], the public cloud, business and application services are expected to reach \$236 billion with a cumulative annual growth rate of $22 \%$ between 2015 and 2020. The market for cloud applications will grow faster. It is expected that in 2020, it will be $17 \%$ higher than in 2014. Cloud costs of enterprise grow at average annual accumulated rate of $16 \%$ between 2016 and 2026 [13].

\subsection{Blockchain technology}

Blockchain is a new technology on distributed software architecture. In blockchain networks, the members can find agreement on sharing status to distribute and share transaction data across large networks of untrusted stakeholders. It does not have to depend on a reliable central point for every member of the system. Blockchain is a block list with a time stamp that records the history and aggregate information about transactions that have occurred within the blockchain network. Therefore, blockchain provide unmodified storage. It is only possible to add or update a transaction without deleting the transactions that appear in blockchain to prevent tampering and modification [14]. According to the reliability features of the blockchain, it has become the core of today cryptocurrency. Bitcoin is the first cryptocurrency to use blockchain successfully. The blockchain has its origins in a white paper called "Bitcoin: A Peerto-Peer Electronic Cash System" [15]. In general, blockchain information is stored on each node of an interconnected peer-to-peer network and certify to record new data by using the consensus mechanism. 


\subsection{Open digital labor market}

According to reports from Pew Research Center [16], 54\% of Americans uses online search to find work. The Internet is current source of job seekers and $79 \%$ uses online resources to find their latest jobs. Moreover, it is found that Americans use social media to search for jobs, share opportunities with their friends, and focus on their skills to those who expect to be an employer. $35 \%$ used social media to search for jobs, while $21 \%$ applied for jobs that were newly discovered through social media. $13 \%$ of social media users said they used social media to search for jobs while $21 \%$ applied for their first job search through social media, and 31\% used social media to send to friends about vacancies at the companies they worked for.

According to one sample country about labor report as USA above, it can be concluded that the current digital labor market is the convergence of demand and supply of labor with digital environment. Therefore, the open digital labor market is the labor market platform for job seeker and employers to search each other freely through the Internet, e.g. web applications, mobile applications, and social media.

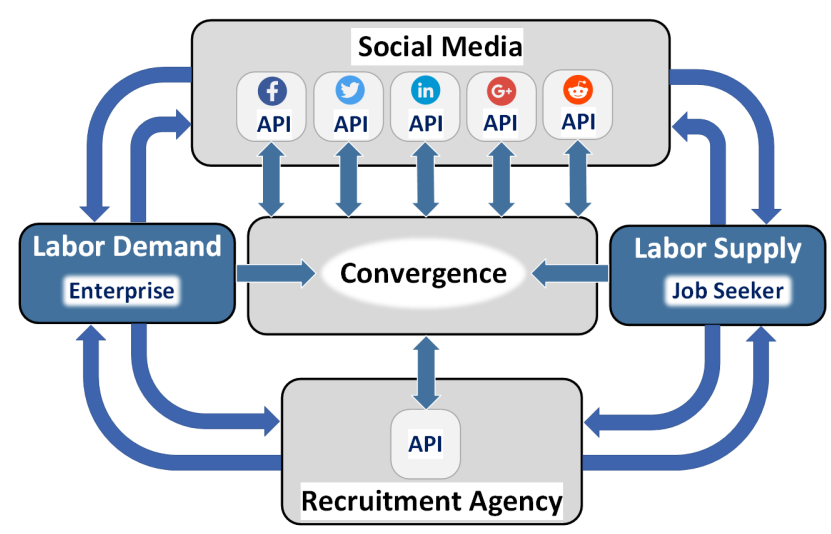

Fig. 1. Structure of open digital labor market

Figure.1. shows the structure of the open digital labor market, which has four main components: labor demand, labor supply, social media, and recruitment agency. The demand and supply of labor can be met directly by traditional channels, but social media is a new channel. Meanwhile, social media has an application programming interface (API) that makes it possible for third parties to exchange information.

\section{Research Methodology}

The design process of cooperative education management system through the cloud-based blockchain E-Portfolio has the following steps.

- Investigation of research paper

- Identifying the problem and cause effect analysis 
- Design of conceptual framework

- Process design of cooperative education management system

\subsection{Investigation of research paper}

The information systems help to documents and related works for cooperative education since the 1980s. There are many researches concerning the assessment of EPortfolio in cooperative education and work-integrated learning from 2005 to 2017, e.g. Jorgenson \& Senini [17], Hodges [18], Hayward et.al. [19], Johrendt et.al. [20], Jaekel et.al. [21], Koch [22], McNamara [8], Robles \& Alanson [23], and Jackson et.al. [24]. the following interesting statistics are obtained:

Table 1. Summarization of assessment component in cooperative education E-Portfolio from research study from 2005 to 2017

\begin{tabular}{|c|c|c|c|c|c|c|c|c|c|c|c|}
\hline & C1 & C2 & C3 & C4 & C5 & C6 & C7 & C8 & C9 & C10 & C11 \\
\hline R1 & & & 1 & 1 & 1 & 1 & & 1 & & & 1 \\
\hline R2 & 1 & 1 & 1 & 1 & & 1 & & & 1 & 1 & \\
\hline R3 & & & 1 & & & 1 & & & 1 & 1 & \\
\hline R4 & 1 & 1 & & & 1 & 1 & 1 & 1 & & 1 & \\
\hline R5 & 1 & 1 & 1 & 1 & 1 & 1 & 1 & 1 & 1 & 1 & \\
\hline R6 & & 1 & 1 & & 1 & 1 & 1 & & & 1 & \\
\hline R7 & 1 & 1 & 1 & & 1 & 1 & & 1 & & 1 & 1 \\
\hline R8 & 1 & 1 & 1 & & & 1 & 1 & 1 & 1 & & \\
\hline R9 & & & & & 1 & 1 & & & & 1 & 1 \\
\hline (n) & 5 & 6 & 7 & 3 & 6 & 9 & 4 & 5 & 4 & 7 & 3 \\
\hline$\%$ & 55.56 & 66.67 & 77.78 & 33.33 & 66.67 & 100.00 & 44.44 & 55.56 & 44.44 & 77.78 & 33.33 \\
\hline
\end{tabular}

*Components: $\mathbf{C 1}=\mathrm{CV} /$ Resume, $\mathrm{C} 2=$ Employer assessment, $\mathrm{C} 3=$ Self-assessment, $\mathrm{C} 4=$ Peer assessment, $\mathrm{C} 5=$ Oral Presentation, $\mathrm{C} 6=$ Written reports, $\mathrm{C} 7=$ Rubrics, $\mathrm{C} 8=$ Interview, $\mathrm{C} 9=$ Peer review, $\mathrm{C} 10=$ Work/Career planning, C11= Record Book.

*Research: R1=Jorgenson\&Senini, R2=Hodges, R3=Hayward et.al., R4=Johrendt et.al., R5=Jaekel et.al., R6=McNamara, R7=Koch, R8=Robles\&Alanson, R9=Jackson et.al.

Table 1. shows that written report, self-assessment, job/career planning, employer assessment, oral presentation, and interview are most popular component.

\subsection{Identifying problem and cause effect analysis}

The research study of previous step has revealed several facts. Firstly, the cooperative education information systems in higher education institutes are independently developed so there are unshared information resources. Secondly, it does not appear publicly available of the information. Thirdly, it overlooks 21 st century learning skills. The findings and cause effect analysis are summarized as follows.

The lack of information resource sharing among higher education institute: According to investigation of research study, it has shown that most of the information system of the higher education institutions in cooperative education are similar 
and have the same purpose on business. However, if it changes from competition to coalition, in addition to costs reducing, sharing economy makes the allocation of resources effectively as well [25].

The lack of information connection to the public: The research study shows that all cooperative education systems were developed to use only their own programs. Even though authentic assessment evidence in the system can be used to apply for job in the future, but was abandoned unfortunately. The cause of this problem is digital data is easy to counterfeit so it lack of reliability.

The lack of enhancing the 21st century learning skill: The different social and economic conditions between 20 th century and 21 st century is the cause that cooperative education always overlook the new importance skills in the new century and only focus on professional skills. The skill of information, media, and technology is one of the 21 st century learning skills that are often overlooked, so do digital competence are overlooked as well.

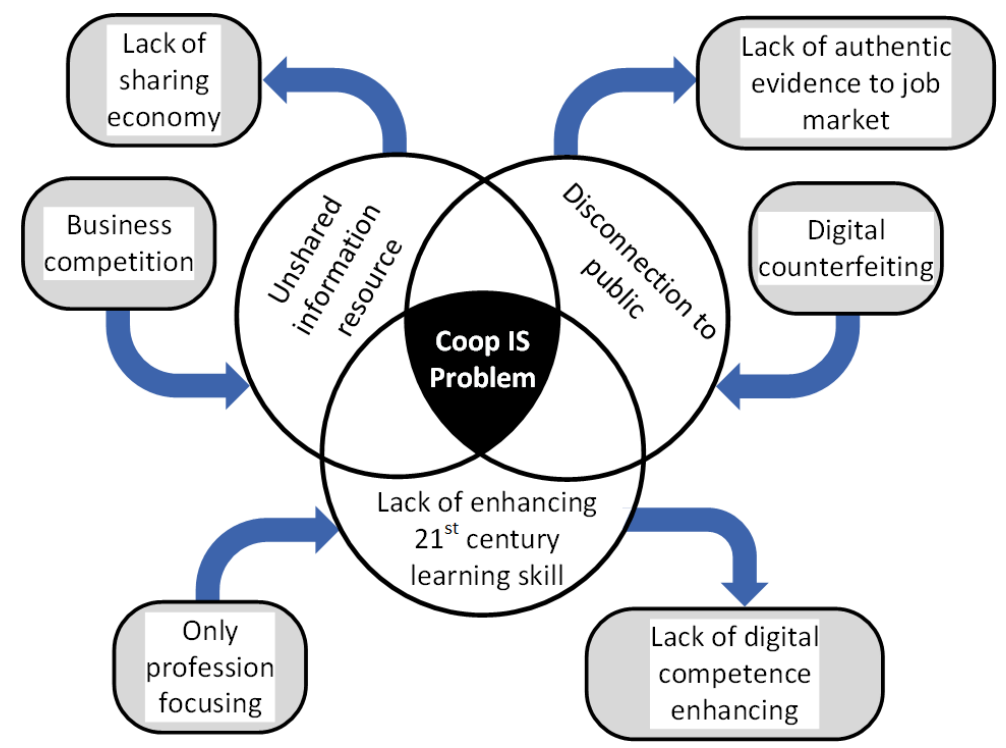

Fig. 2. The summarization of problems, causes, and effects in cooperative education information system

Figure.2. shows three main problems in the cooperative education information system; each problem has different causes and effects. The arrow symbol running into the circle is the cause and the arrows running out of the circle is the effect. In the case of unshared information resource, the business competition is the cause of unshared information resource and unshared information resource is the cause of loss opportunity in sharing economy. In the case of disconnection to public, the digital counterfeiting is the cause of disconnection to public and disconnection to public is the cause of lack of authentic evidence on the labor market. In the case of lack of enhancing 21 st century learning skill, the only profession focusing is the cause of loss opportuni- 
ty in enhancing 21 st century learning skill and loss opportunity in enhancing 21 st century learning skill is the cause of loss opportunity in digital competence enhancing. The analyzing of causes and effects can be summarized as follows:

\section{Problem 1:}

- "Business competition" $\rightarrow$ "Unshared information resources"

- "Unshared information resources" $\rightarrow$ "Lack of sharing economy"

\section{Problem 2:}

- "Digital counterfeiting" $\rightarrow$ "Disconnection to public"

- "Disconnection to public" $\rightarrow$ "Lack of authentic evidence to the job market"

\section{Problem 3:}

- "Only profession focusing" $\rightarrow$ "Lack of enhancing 21st learning skill"

- "Lack of enhancing 21st learning skill" $\rightarrow$ "Lack of digital competence enhancing"

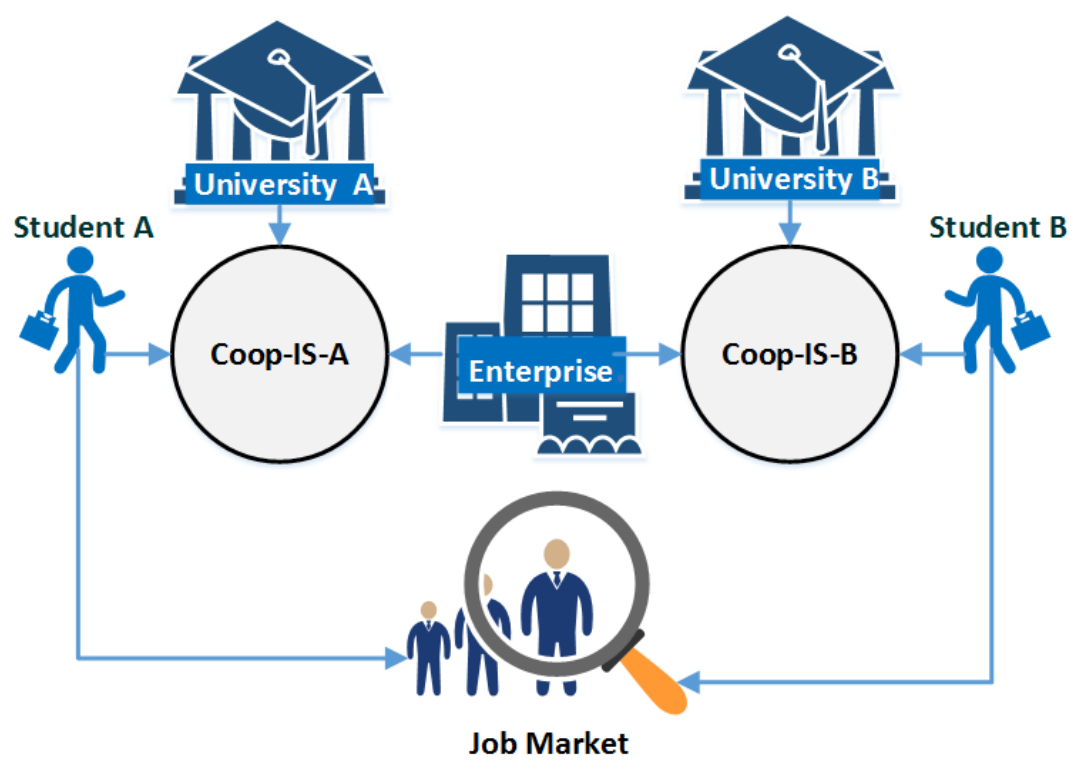

Fig. 3. Problem of unshared information resources among higher education institutes

Figure.3. shows two students from two universities are entering to cooperative education program at the same workplace. Even though the cooperative education information systems of both universities have the same function, but both universities have unshared information resources. When students from both universities graduate and apply for job market, the digital evidence of both universities' systems was not publicly available to the job market. The cause of digital evidence is not publicly available is because the ease of tampering that make it lack of credibility. 


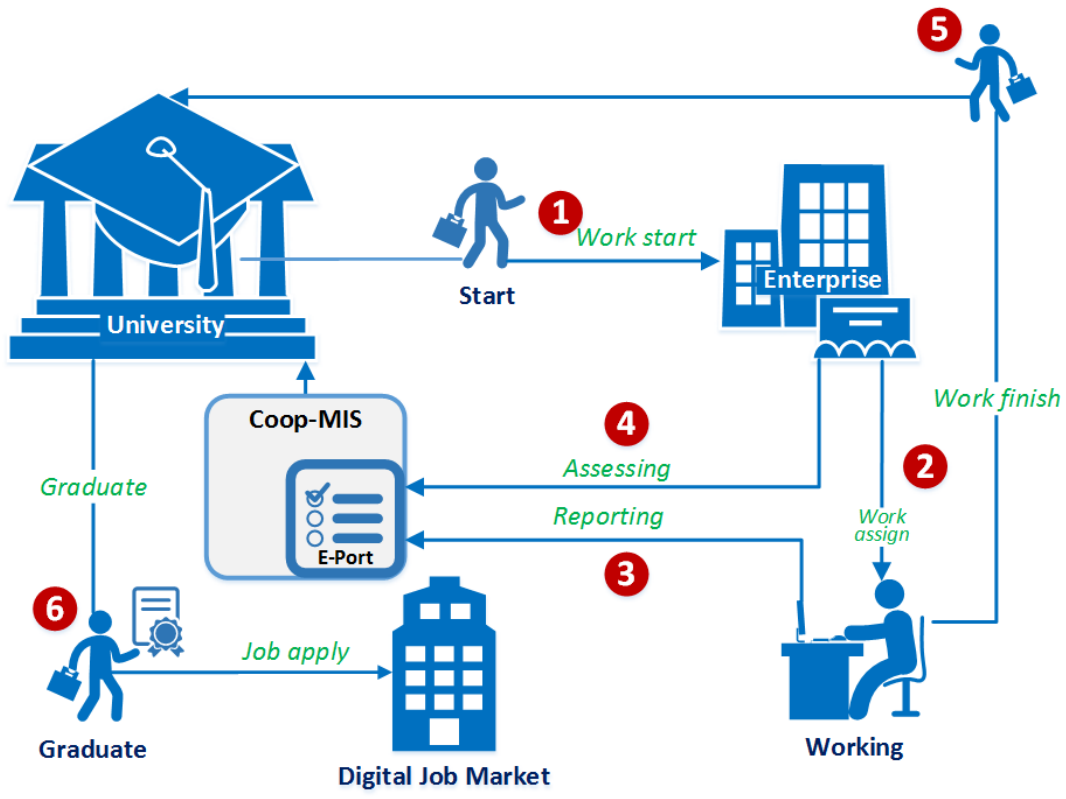

Fig. 4. Problem of disconnection of cooperative education information system to digital job market

Figure.4. shows information systems are digitally archived, but disconnection to the digital labor market.

- Starting of cooperative education program

- Assigning the task to student

- The task report

- Assessing every task of students

- Ending of program

- Students graduate and entering to the digital labor market by applying for job with paper-based evidence. The evidence of experience, cooperative education, and performance assessment are in the digital form of management information systems that are ready to be exploited, but there are unfortunately neglected.

\subsection{Design of conceptual framework}

The conceptual framework is based on the system approach by divided into three elements: input, processing, and output.

1. The input element is consisting of three stakeholders of cooperative education, technologies, and digital competence framework 2.0. The stakeholders of cooperative education include student, faculty, and mentor of workplace. The technologies include E-Portfolio, cloud computing technology and blockchain technology. 
2. The process element is consisting of task assessing process for digital competence through E-Portflio and recorded to blockchain to increase reliability.

3. The output element is reliable result of digital competence, which can be considered by the labor market for recruitment.

The findings from investigation of research paper on previous step were taken for consideration by selection components corresponds to the context, written report (100\%), employer assessment (66.67\%) and rubrics (44.44\%) are integrated.

- Written report $\rightarrow$ Task report in E-Portfolio

- Rubrics $\rightarrow$ transforming digital competence to assessment criteria of E-Portfolio

- Employer assessment $\rightarrow$ E-Portfolio and rubrics integration to assessment form

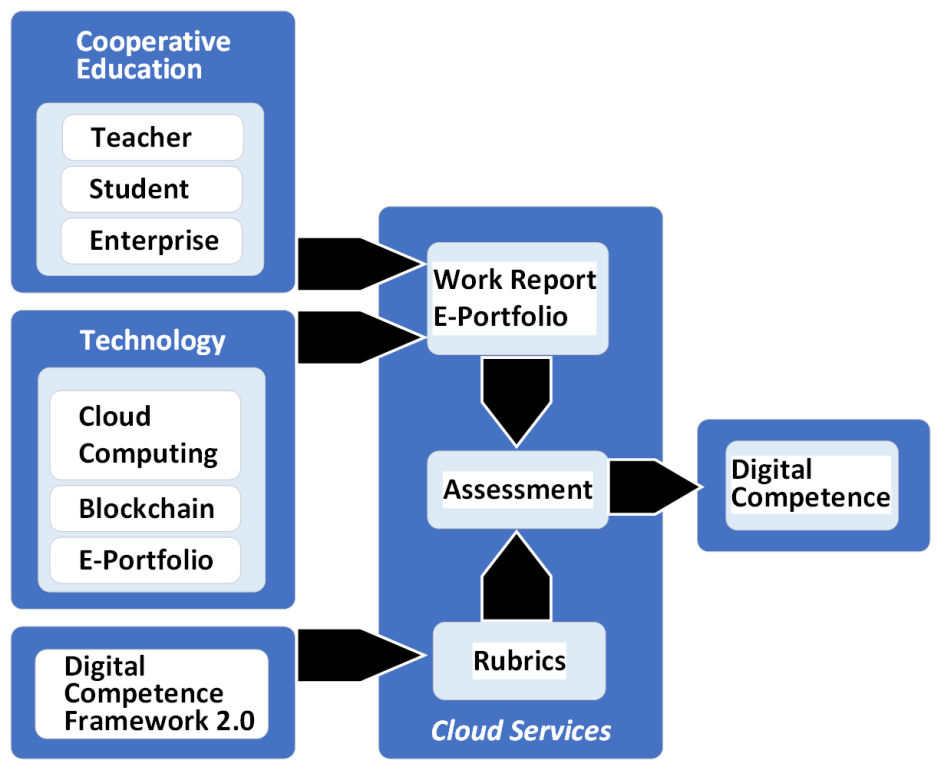

Fig. 5. Conceptual framework of digital competence assessing through blockchain E-Portfolio of cooperative education

\subsection{Process design of cooperative education management system}

Once conceptual framework is created, the next step is to implement the conceptual framework for designing the process of addressing three problems encountered in cooperative education information systems as follows:

The solution for unshared information resource among higher education institutes: The solution to the problem of unshared information resource among higher education can be solved by developing a central information system that can be shared among communities of higher education institutes.

The solution for disconnection of information resource to public: The disconnection of information resource to public from the cause of data in digital format is 
easy to counterfeit is solved by using blockchain technology to store transaction of EPortfolio to enhance credibility in the digital labor market.

The solution for lack of enhancing to the 21 st century learning skill: The solution to the problem of lose opportunity in enhancing to $21^{\text {st }}$ century learning skills is extracting the digital competence framework 2.0 to the rubric and integrate with cooperative education E-Portfolio to create an assessment form of the student digital competence.

\section{$4 \quad$ Result}

\subsection{The process of information resource sharing among universities}

According to changing perspectives from business competition to business sharing in addition to reduce the overall cost, information from this central system can also be shared with the public.

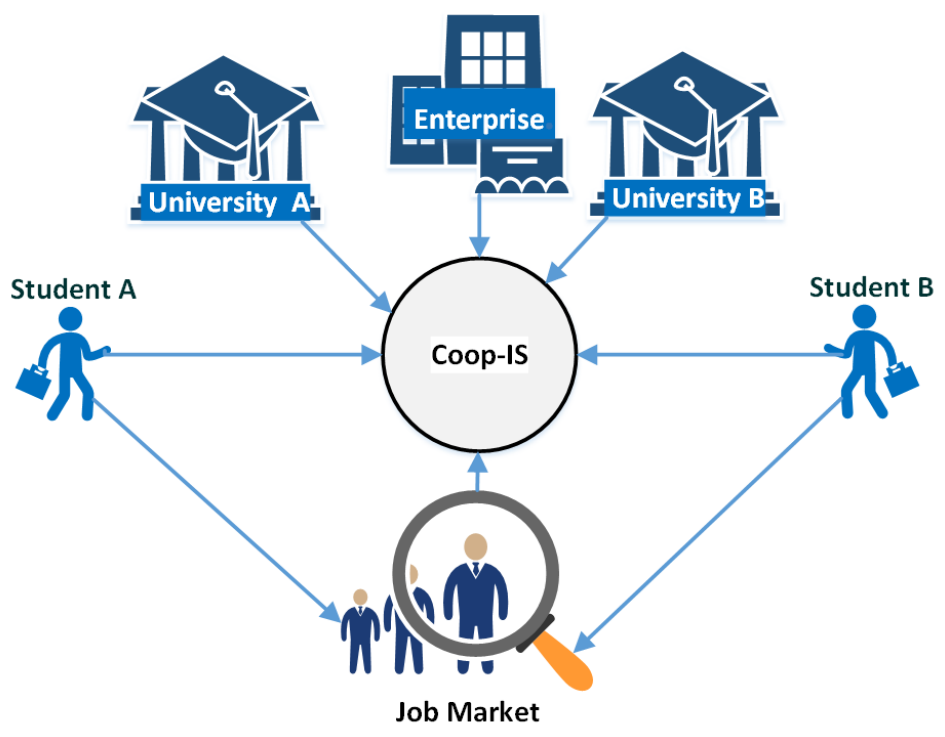

Fig. 6. The central management information system of cooperative education

Figure.6. show that students in the cooperative education program from both universities, regardless of their workplace, use the same cooperative education information system. All information can be shared and benefits from sharing economy.

\subsection{The process of information connection to the public}

Although the development of centralized cooperative education information systems will benefit from sharing economy and more benefit to public sharing especially 
labor markets, but the nature of digital data is easy to counterfeit, make digital evidence unreliable. As seen, even job application is online, but the paper evidence must be sent later. Therefore, blockchain technology has played a role in capturing transaction of working evidence and digital competence assessment because blockchain has a mechanism that makes it hard to counterfeit.

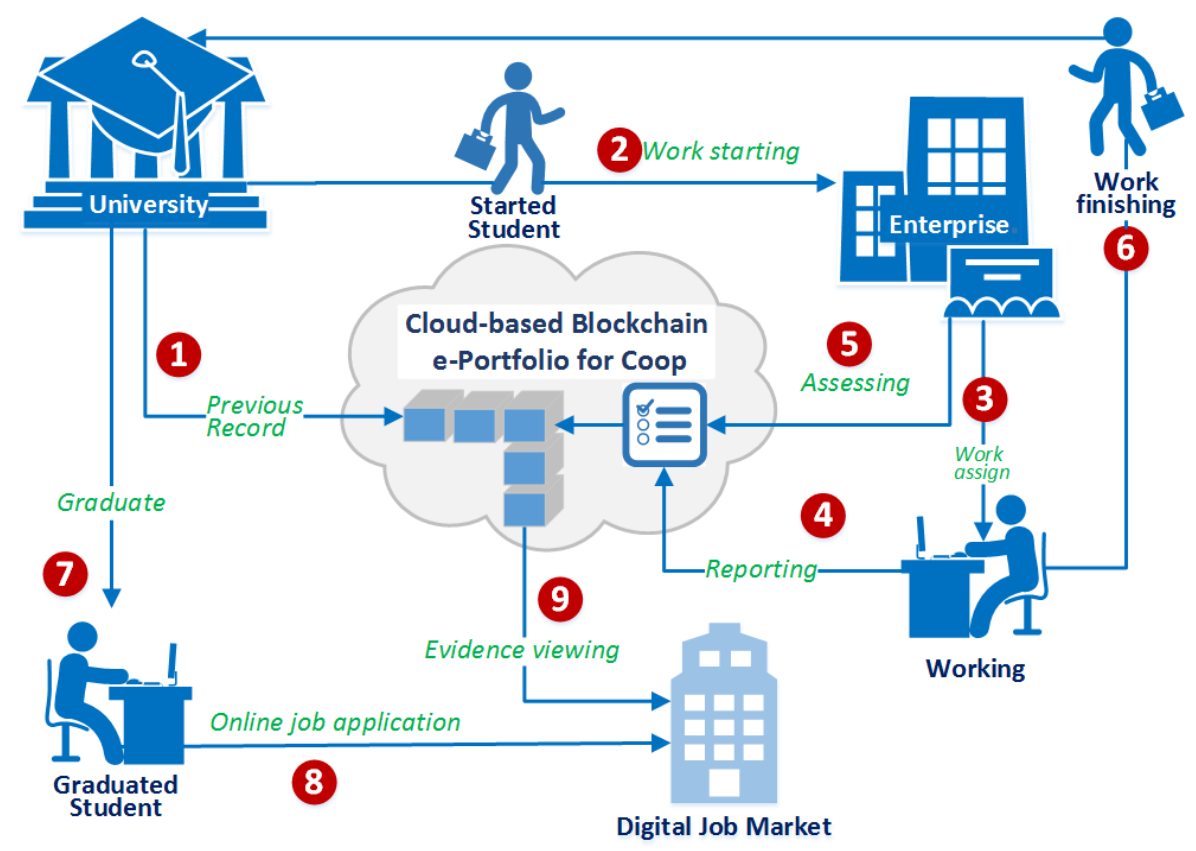

Fig. 7. The management of cooperative education through cloud-based blockchain E-Portfolio

Figure.7. shows the information sharing of cooperative education in the digital labor market through the use of blockchain technology. (1) starting from the previous information of students in the cooperative education program will be recorded into blockchain, (2) when the student initiates the cooperative education program, and (3) task assigning and, (4) task reports are recorded, (5) before recording transaction into blockchain, task report will be assessed by the workplace mentor, (6) when student finish the program (7) of cooperative education program and graduation (8) then apply to online job, (9) the digital labor market is able to retrieve evidence of study experience and result of digital competence assessment from the central system immediately. The blockchain make it credible finally.

\subsection{The process of enhancing 21 st century learning skill}

The 21st century learning skill especially the skill of information, media and technology are important tools for living, working, and developing other skills. This re- 
search has introduced the digital competence framework 2.0 as a tool to support the skill of information, media, and technology.

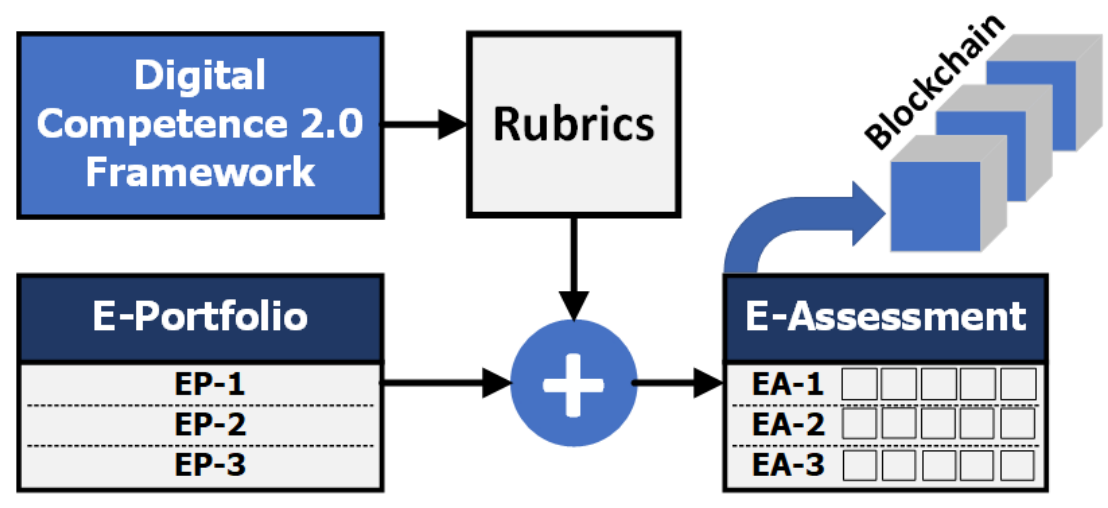

Fig. 8. The creating of E-Assessment form by integration of cooperative education E-Portfolio and digital competence framework 2.0

Figure.8. shows the digital competence framework is extracted into a rubric for assessing E-Portfolio. When rubrics and E-Portfolio are combined, the E-Assessment form will be created and assessment results are recorded to blockchain.

\section{Conclusion}

The process design of this research enable to solve three problems in cooperative education information systems, unshared information resources, disconnection to public, and lack of enhancing 21 st century learning skill especially information, media, and technology. In addition to the sharing economy, this system can connect information to the public and enhance digital competence by the assessment of cooperative education E-Portfolio. Finally, blockchain come to increase the credibility of assessment evidence to the open digital labor market.

\section{Acknowledgement}

This research was supported by the Faculty of Technical Education, Vocational Education Technology Research Center, Innovation and Technology Research Center at Science and Technology Research Institute, King Mongkut's University of Technology North Bangkok, Thailand. 


\section{$7 \quad$ References}

[1] P21, "Framework for 21st Century Learning," 2007. [Online]. Available: http://www.p21.org/about-us/p21-framework. [Accessed 10 January 2018].

[2] DESI, "DESI indicator on "digital skills"," 2015. [Online]. Available: http://digital-agendadata.eu/datasets/desi/indicators.

[3] Weisz, M., \& Smith, S., "Critical changes for successful cooperative education," in Higher education in a changing world. Proceedings of the 28th HERDSA Annual Conference, 2005, July.

[4] Ruiz, J. H., Koch, C., Erthal, M., \& Williams, M., "Handbook for Cooperative Education, Internships, and Registered Apprenticeship." 2009. [Online]. Available: http://www.partners4value.lt/wp-content/uploads/2015/10/Handbook-for-CooperativeEducation-Internships-and-Registered-Apprenticeship.pdf. [Accessed 13 August 2018].

[5] Marcoul-Burlinson,I., Handbook of research on eportfilios, London, UK: Idea Group, 2006, pp. 1-14.

[6] Mcdermott, K., \& Gallagher, S., "Asia-Pacific Journal of Cooperative Education," Integration of eportfolios into cooperative education: Lessons learnt, vol. 12, no. 2, pp. 95-101, 2011.

[7] Alanson, E. R., \& Robles, R. A., "Using Electronic Portfolios to Explore Essential Student Learning Outcomes in a Professional Development Course," Asia-Pacific Journal of Cooperative Education, vol. 17, no. 4, pp. 387-397, 2016.

[8] McNamara,J., "The challenge of assessing professional competence in work integrated learning," Assessment \& Evaluation in Higher Education, vol. 38, no. 2, pp. 183-197, 2013. https://doi.org/10.1080/02602938.2011.618878

[9] Van den Brande, L, "The European Digital Competence Framework for citizens. 10.13140/RG.2.1.4687.1281.," 2016. [Online]. Available: https://www.researchgate. net/profile/Lieve_Van Den_Brande/publication/305992028 The European_Digital_Com petence_Framework_for_citizens/links/57a89c4108ae0107eee6c932/The-EuropeanDigital-Competence-Framework-for-citizens.pdf?origin=publication detail. https://doi.org/10.4018/978-1-4666-0903-7.ch005

[10] Vuorikari, R., Punie, Y., Carreteto. G. S., \& Vand Den Brande, G., "DigComp 2.0: The Digital Competence Framework for Citizens," 2016. [Online]. Available: https://ec.europa.eu/jrc/en/printpdf/150698. [Accessed 14 August 2018].

[11] Wong,T.L., Hoang,T.,\& Steven, G., "A Fresh Graduate's Guide to Software Development Tools and Technologies, Chapter 1 Cloud Computing," 2012. [Online]. Available: https://www.comp.nus.edu.sg/ seer/book/2e/. [Accessed 14 August 2018].

[12] Bartels, A., Bartoletti, D., \& Rymer, J., "Public Cloud Market Will Grow to \$236 Billion in 2020," 1 September 2016. [Online]. Available:

https://www.forrester.com/Public+Cloud+Market+Will+Grow+To+236+Billion+In+2020/ -/E-PRE9446.

[13] Burris, P., "Wikibon report preview: How big can Amazon Web Services get?," 20 February 2017. [Online]. Available: https://siliconangle.com/2017/02/20/wikibon-reportpreview-big-can-amazon-web-services-get/.

[14] Xu, X., Pautasso, C., Zhu, L., Gramoli, V., Ponomarev, A., Tran, A. B., \& Chen, S, "The blockchain as a software connector," in 2016 13th Working IEEE/IFIP Conference on Software Architecture (WICSA), 2016, April. https://doi.org/10.1109/wicsa.2016.21

[15] Nakamoto,S., "Bitcoin: A peer-to-peer electronic cash system.," 2008. [Online]. Available: https://bitcoin.org/bitcoin.pdf.

[16] Smith,A., "Searching for Work in the Digital Era," 19 November 2015. [Online]. Availa- 
ble: http://www.pewinternet.org/2015/11/19/searching-for-work-in-the-digital-era/.

[17] Jorgensen, D., \& Senini, S., "Confronting the assessment demon-engineering portfolio assessment," in 4th ASEE/AaeE Global Colloquium on Engineering Education , 2005.

[18] Hodges, D., "Letting go: Changing ownership of the learning and assessment process in cooperative education," in Proceedings of the 11th Annual Conference of the New Zealand Association for Cooperative Education, 2008, April.

[19] Hayward, L. M., Blackmer, B., Canali, A., Dimarco, R., Russell, A., Aman, S.,Rossi, J., \& Sloane, L., "Reflective electronic portfolios: a design process for integrating liberal and professional studies and experiential education," Journal of allied health, vol. 37, no. 3, pp. 140-159, 2008.

[20] Johrendt, J., Singh, P., Hector, S., Watters, M., Salinitri, G., Benzinger, K., Jaekel,A., \& Northwood, D., "The Co-Op portfolio: An essential tool for assessment and student development in co-operative engineering programs," in 20th Annual Conference for for the Australasian Association for Engineering Education, 6-9 December 2009: Engineering the Curriculum, Engineers, Australia, 2009.

[21] Jaekel, A.., Hector, S., Northwood, D., Benzinger, K., Salinitri, G., Johrendt, J., \& Watters, M., "Development of learning outcomes assessment methods for co-operative education programs," Journal of Cooperative Education and Internships, vol. 45, no. 1, pp. 11-33, 2011.

[22] Koch, A., "E-Portfolios within Work-Integrated Learning: Online performance appraisal of final year students. In Proceedings of 9th WACE International Conference," Turkey, 2012, June.

[23] Robles, A., \& Alanson, E, "ePortfolio Implementation for Career Education," The Journal for Research and Practice in College Teaching, vol. 1, no. 2, pp. 1-12, 2016.

[24] Jackson, J., Jones, M., Steele, W., \& Coiacetto, E., "How best to assess students taking work placements? An empirical investigation from Australian urban and regional planning," Higher Education Pedagogies, vol. 2, no. 1, pp. 131-150, 2017. https://doi.org/10.1080/23752696.2017.1394167

[25] Felson, M., \& Spaeth, J. L., "Community structure and collaborative consumption: A routine activity approach," American behavioral scientist, vol. 21, no. 4, pp. 614-624, 1978. https://doi.org/10.1177/000276427802100411

\section{Authors}

Sukosol Wanotayapitak is a Ph.D. candidate in ICT for Education at Faculty of Technical Education, King Mongkut's University of Technology North Bangkok, Bangkok, Thailand. (Email: sukosol@yahoo.com)

Kobkiet Saraubon works as teacher at Faculty of Applied Science, King Mongkut's University of Technology North Bangkok, Bangkok, Thailand. (Email: kobkiat.s@sci.kmutnb.ac.th)

Prachyanun Nilsook works as associate professor at Faculty of Technical Education, King Mongkut's University of Technology North Bangkok, Bangkok, Thailand. (Email: prachyanunn@kmutnb.ac.th)

Article submitted 2019-02-28. Resubmitted 2019-04-14. Final acceptance 2019-04-14. Final version published as submitted by the authors. 